\title{
Short-term very low-calorie diet in obese females improves the haemostatic balance through the reduction of leptin levels, PAI-1 concentrations and a diminished release of platelet and leukocyte-derived microparticles
}

\author{
O Morel $^{1,2,3}$, F Luca $^{4}$, L Grunebaum ${ }^{5}$, L Jesel ${ }^{1}$, N Meyer $^{6}$, D Desprez ${ }^{5}$, S Robert ${ }^{7}$, F Dignat-George ${ }^{7}$, \\ F Toti ${ }^{2,3,8}$, C Simon ${ }^{4,9}$ and B Goichot ${ }^{4}$

\begin{abstract}
${ }^{1}$ Pôle d'activité médico-chirurgicale Cardiovasculaire des Hôpitaux Universitaires de Strasbourg, Nouvel Hôpital Civil, place de l'Hôpital, Université de Strasbourg, Strasbourg, France; ${ }^{2}$ Institut d'Hématologie et d'Immunologie, Faculté de Médecine, Université de Strasbourg, Strasbourg, France; ${ }^{3}$ U.770 INSERM, Le Kremlin-Bicêtre, France; ${ }^{4}$ Pôle de Médecine Interne et de Nutrition des Hôpitaux Universitaires de Strasbourg, Strasbourg, France; ${ }^{5}$ Département d'Hémostase des Hôpitaux Universitaires de CHU Hautepierre, Strasbourg, France; ${ }^{6}$ Département de Biostatistique, Faculté de Médecine, Université de Strasbourg, Strasbourg, France; ${ }^{7}$ Faculté de Pharmacie, Université de la Méditerranée, Marseille, France; ${ }^{8}$ Faculté de Médecine Paris-Sud, Université Paris-Sud 11, Paris, France and ${ }^{9}$ Université de Lyon Lyon, INSERM/U870 INRA/U1235, CRNH Rhône-Alpes, Hospices Civils de Lyon, Oullins, France
\end{abstract}

Background: In obesity, metabolic stress and inflammation in injured tissues could favour enhanced shedding of procoagulant microparticles (MPs). At sites of endothelium injury, the swift recruitment of procoagulant leukocyte-derived MPs enables the initiation of blood coagulation and thrombus growth.

Objectives: In obese females, we sought to evaluate the impact of a very low-calorie diet (VLCD) on procoagulant MP levels, fibrinolytic status, inflammation and endothelium damage.

Methods: Circulating biomarkers of vascular damage, fibrinolytic status, platelet activation and inflammation were measured before, 30 and 90 days after starting a short-term VLCD. MPs were measured by flow cytometry and capture assays. Their procoagulant potential was quantified using functional prothrombinase assays and their cellular origin were determined using flow cytometry (endothelium, platelet, leukocyte, lymphocyte and erythrocyte-derived MP) or capture assays.

Results: A total of 24 obese females ( $39 \pm 10$ years) with a mean body mass index of $35 \pm 4 \mathrm{~kg} \mathrm{~m}^{-2}$ were prospectively enroled. Procoagulant leukocyte-derived MPs were associated with the waist circumference at baseline $(r=0.534 ; P=0.010)$ and at 90 days follow-up $(r=0.487 ; P=0.021)$. At 90 days, weight reduction $(-9.8 \%)$ was associated with a lowering of blood pressure, improvement of metabolic parameters and a significant reduction of plasminogen activator inhibitor-1 (PAI-1) (-38\%), procoagulant platelet-derived MPs $(-43 \%)$, leukocyte-derived MPs $(-28 \%)$ and leptin $(-32 \%)$ levels.

Conclusion: In obese females, a short-term VLCD results in an overall improvement of the haemostatic balance characterized by the reduction of PAI-levels, diminished release of platelet and leukocyte-derived MPs and a reduction in leptin levels, an adipocyte-derived cytokine.

International Journal of Obesity (2011) 35, 1479-1486; doi:10.1038/ijo.2011.19; published online 8 March 2011

Keywords: apoptosis; thrombosis; endothelium; leukocyte; metabolic syndrome; coagulation

Correspondence: Professor O Morel, Pôle d'activité médico-chirurgicale Cardiovasculaire des Hôpitaux Universitaires de Strasbourg, Nouvel Hôpital Civil, place de l'Hôpital, Université de Strasbourg, Strasbourg, Cedex 67091, France.

E-mail: olivier.morel@chru-strasbourg.fr

Received 27 September 2010; revised 7 January 2011; accepted 16 January 2011; published online 8 March 2011

\section{Introduction}

Obesity is intimately linked to insulin resistance, type 2 diabetes, vascular inflammation and atherothrombosis. ${ }^{1}$ Dysregulation of various protein secretions, such as leptin, tumour necrosis factor- $\alpha$ and plasminogen activator 
inhibitor-1 (PAI-1) by the adipocyte has been suggested to have a pivotal role in enhanced inflammation, vascular damage and subsequent thrombogenicity. ${ }^{2}$ In obesity, a preliminary report by our group has suggested that metabolic and inflammatory-mediated tissue injury could favour the release of procoagulant microparticles (MPs). ${ }^{3}$ Likewise, in the metabolic syndrome, platelet-derived MPs were found associated to the severity of the syndrome. ${ }^{4}$ In the vessel, MPs increase the catalytic procoagulant surface relying on the essential presence of phosphatidylserine for optimal haemostatic response. At sites of endothelium injury, the swift recruitment of leukocyte-derived procoagulant MPs enables the concentration of tissue factor activity leading to blood coagulation and thrombus growth. ${ }^{5}$ When generated at high levels, circulating MPs were demonstrated to be potent effectors in the development of atherothrombosis by supporting cellular cross-talk involved in vascular inflammation and tissue remodelling, endothelial dysfunction, leukocyte adhesion and monocyte diapedesis within the plaque. ${ }^{5}$

Various pathways susceptible to metabolic stress and inflammation could contribute to MP release and thrombotic propensity in obesity. For instance, by releasing tumour necrosis factor- $\alpha$, the adipocyte directly suppresses insulin signalling, induces insulin resistance and could promote the shedding of procoagulant MPs by endothelial cells or monocytes. Besides its role in the development of adipose tissue and in the control of adipocyte insulin signalling, elevated plasma levels of PAI-1 in obese individuals could also contribute to the disruption of the haemostatic balance by preventing efficient fibrinolysis. ${ }^{6}$ Moreover, the demonstration of the reduction of PAI-1 or platelet-derived MPs plasma levels through weight loss paves the way to a possible therapeutic target for controlling cardiovascular morbidity in obese subjects. ${ }^{7,8}$ To further characterize the relationship between obesity and the thrombotic risk, we sought to evaluate the impact of a short-term very low-calorie diet (VLCD) on procoagulant MP levels, fibrinolytic status, inflammation and endothelium damage. Given the prime importance of leukocyte shedding in the formation of the thrombus, special attention was paid to the variation of leukocyte-derived MPs levels.

\section{Subjects and methods}

\section{Subjects}

The local medical ethics committee approved the study protocol and written informed consent was obtained from each subject according to the declaration of Helsinki.

The study was an open trial including a total of 24 obese females (aged 39 \pm 10 ) admitted to the department of Nutrition and Internal Medicine at the Hôpitaux Universitaires de Strasbourg. Inclusion criteria were a body mass index (BMI) $>30 \mathrm{~kg} \mathrm{~m}^{-2}$ and age between $18-70$ years. Exclusion criteria were a history of cardiovascular disease or ischaemic complications, type 1 diabetes mellitus, inflammatory disease and neoplasia. Anthropometric measurements including weight, BMI, waist and hip circumference together with blood sampling were carried out at D0, D30 and D90. Fat mass was evaluated by impedancemetry (Tanita 310, Tanita, Tokyo, Japan). Energetic expenditure was calculated using indirect calorimetry (Deltatrac, Datex-Ohmeda, Madison, WI, USA). At D0, the subjects were instructed to take Insudiet $(600 \mathrm{kcal}$ per day, proteins $75 \mathrm{~g}$ per day, lipids $10 \mathrm{~g}$ per day, glucids $40 \mathrm{~g}$ per day) for 1 month, (1200 kcal per day, proteins $80 \mathrm{~g}$ per day, lipids $15 \mathrm{~g}$ per day, glucides $170 \mathrm{~g}$ per day) during the second month. After that, a progressive reintroduction of normal intake was recommended. Patients were examined by an investigator and a dietician every 10 days during the first month and then once a month until the end of the study. Insulin resistance was defined by an homeostasis model assessment index $>2.4$ (plasma glucose $\times$ insulinemia plasma/22.5) .

\section{Blood sampling and plasma preanalytical treatment}

Blood samples were drawn into $0.129 \mathrm{moll}^{-1}$ sodium citrate tubes (Vacutainer, Becton Dickinson, Le Pont de Claix, France) and processed according to the International Society of Thrombosis and Haemostasis recommendations for MP analysis. ${ }^{9}$ Briefly, platelet-free plasma was obtained after an initial centrifugation at $1500 \mathrm{~g}$ for $15 \mathrm{~min}$ followed by a $2 \mathrm{~min}$ centrifugation at $13000 \mathrm{~g}$ and was aliquoted and frozen $\left(-80^{\circ} \mathrm{C}\right)$ until required for analysis.

\section{Isolation of circulating MPs, determination of their cellular} origin and functional assessment of their procoagulant activity MPs were isolated either by capture on insolubilised annexin-5 or using specific antibodies. Both ligands (antibodies or annexin-5) were separately insolubilised onto streptavidin-coated microtitration plates before incubation with platelet-poor-plasma. Biotinylated annexin-5 has a strong affinity for procoagulant phosphatidylserine accessible at the MP surface. As phosphatidylserine is a ubiquitous feature of procoagulant MPs, it provides information on the total amount of circulating procoagulant MPs, regardless of their cellular origin. The quantity of MPs captured onto biotinylated monoclonal antibodies gives an additional indication of their cellular origin and the cellular response to vascular stress. In the present study, the following biotinylated monoclonal antibodies were used: CD11a (leukocytes), CD31 (endothelial cells and platelets) and GPIb (platelets). During MP quantitation, the background reactivities to isotypic irrelevant IgG were subtracted from all values.

After platelet-poor-plasma incubation and the washing steps, annexin-5 and antibody-captured procoagulant MPs were quantified using a functional prothrombinase assay. This assay measures the procoagulant phosphatidylserine content of MPs through its ability to promote the activation of prothrombin to thrombin in a calibrated purified system ensuring that phosphatidylserine is the rate-limiting 
parameter of the reaction. Briefly, immobilized MPs were incubated with factor $\mathrm{Xa}\left(50 \mathrm{pmoll}^{-1}\right)$, factor $\mathrm{Va}$ $\left(360 \mathrm{pmol}^{-1}\right)$, prothrombin $\left(1.3 \mu \mathrm{moll}^{-1}\right)$ and $2.3 \mathrm{mmol}^{-1}$ $\mathrm{CaCl}_{2}$ in $\mathrm{TBS}-\mathrm{Ca}^{2+}$ containing $45 \mu \mathrm{M}$ human serum albumin at $37^{\circ} \mathrm{C}$. Generated thrombin was assessed by changes in the linear absorbance resulting from the cleavage of a chromogenic substrate $\left(380 \mu \mathrm{mol}^{-1}\right)$. Results were expressed as phosphatidylserine equivalent by reference to a standard curve constructed using liposomes of known concentration. ${ }^{10}$ All tests were performed in duplicate. The solid-phase capture combined with the prothrombinase assay provides a functional assessment of the procoagulant capacity of isolated MPs, regardless of the capture ligand. Truly soluble forms of membrane antigens do not generate prothrombinase activity. ${ }^{10}$ No direct comparison between capture by annexin-5 and monoclonal antibody (mAb) could be performed because preincubation times and affinities for the respective ligands were different. Variations in measurements were routinely $<10 \%$ (identical platelet-poor-plasma sample assayed on 15 separate occasions), regardless of the pathological status and the capture system. All samples underwent a single freeze-thaw cycle. The mAb against human platelet glycoprotein GPIb was kindly provided by Dr François Lanza (U.311 INSERM, Strasbourg, France). Monoclonal antibodies raised against human CD105 (R\&D systems, Minneapolis, MN, USA) were biotinylated in our laboratory. Biotinylated mAbs against CD11a and isotypic irrelevant biotinylated IgG were from Leinco Technologies (Ballwin, MO, USA). Biotinylated mAbs against TF were purchased from American Diagnostica (Stamford, CT, USA). Human prothrombin (FII) was from Hyphen BioMed (Andresy, France), whereas activated factor $\mathrm{X}$ was from Biogenic S.A. (Mauguio, France). Factor Va was obtained from American Diagnostica. High-binding capacity streptavidin-coated microtitration plates and Chromozym TH were purchased from Roche Diagnostics (Mannheim, Germany).

Phenotypic determination of circulating MPs by flow cytometry MP sub-populations were analyzed using selective fluorochrome-labelled antibodies from Immunotech, Beckman Coulter (Marseille, France): anti-GPIIbIIIa for platelet MPs (PMP: phycoerythrin-CD41clone P2), anti-glycophorinA for erythrocyte MP (ErMP: phycoerythrin-CD235a), anti-CD45 for leukocyte MP (LMP: Fluoroisothiocyanate-CD45) and anti-CD31 ${ }^{+} \mathrm{CD} 41^{-}$for endothelial MP and with annexin-5 binding for phosphatidylserine-expressing MPs, whatever their cellular origin (total microparticles expressing phosphatidylserine). After thawing, $30 \mu$ of plasma was incubated with specific monoclonal antibodies or with FITC-annexin-5 or with corresponding isotype-controls (FITC-IgG1 and PE-IgG1). After a 30-min incubation at room temperature, samples were diluted in $1.5 \mathrm{ml}$ of phosphate-buffered saline (Dulbelcco's; Life Technologies, Paisley, UK) or binding buffer for annexin-5 labelling (Beckman Coulter, Immunotech). MPs were counted by flow cytometry (CXP FC500
Beckmann Coulter), according to their size and fluorescence in a LogFS-LogSS dotplot. The flowcount beads were counted in a LogFS-LogFL3 dotplot and used as an internal standard to express MP count as the number of $\mathrm{MP}_{\mu \mathrm{l}}^{-1}$ of plasma.

\section{Miscellaneous measurements}

Quantitative determination of plasma von Willebrand factor antigen was performed using immunoturbidimetric assays. PAI-1 plasma concentrations were determined using a synthetic chromogenic substrate method.

\section{Statistical analysis}

Categorical data are described with number and proportion of subject in each category. Continuous data are described using mean and standard error. Parametric Pearson's or nonparametric Spearman's correlation coefficient were computed. Repeated data were analysed using mixed models. For each model, three variances-covariances were fitted: unstructured, heterogeneous compound symetry and heterogeneous Toeplitz. The choice of the best fitting matrix among the three types was based on the AIC. Significance level was set to 0.05. Computation was done with SPSS 13.0 (SPSS Inc., Chicago, IL, USA).

\section{Results}

Detailed characteristics of the 24 obese female subjects and variations of anthropometrics and biological parameters between D0, D30 and D90 are given in Tables 1 and 2. At baseline, the mean BMI and mean waist circumference were $35 \pm 4 \mathrm{~kg} \mathrm{~m}^{-2}$ and $101 \pm 11 \mathrm{~cm}$, respectively. Leptin levels were related to weight $(r=0.470 ; P=0.020)$, BMI $(r=0.472$; $P=0.020)$, fat mass $(r=0.433 ; P=0.033)$ and vWF levels, a marker of endothelium damage $(r=0.440 ; P=0.031)$. Procoagulant leukocyte-derived MPs were associated with waist circumference at baseline $(r=0.534 ; P=0.010)$ and at D30 $(r=0.679 ; P=0.001)$ and at D90 $(r=0.487 ; P=0.021)$ followup (Figure 1).

Consequences of VLCD on clinical and biological parameters After 90 days of VLCD, a significant body weight loss was observed $(-9.8 \% ; P<0.001)$. Similarly, waist circumference, blood pressure, total cholesterol and triglycerides, fasting plasma glucose, fasting plasma insulin and the homeostasis model assessment index were significantly decreased at D30 and D90 (Table 1).

Consequences of a short-term VLCD on haemostatic and inflammation parameters

Short-term VLCD induced a significant reduction in PAI-1 (-38\%), procoagulant-platelet derived MPs (-43\%) and leptin levels $(-32 \%)$. Consistent with a diminished 
Table 1 Impact of short-term very low-calorie on anthropometric and metabolic parameters

\begin{tabular}{|c|c|c|c|c|c|c|}
\hline & Baseline DO & D30 & $\begin{array}{c}\mathrm{P} \\
\text { (baseline/D30) }\end{array}$ & D90 & $\begin{array}{c}\text { Variation } \\
(D 90-D 0 / D 0), \%\end{array}$ & $\begin{array}{c}\mathrm{P} \\
\text { (baseline/D90) }\end{array}$ \\
\hline Age (years) & $39 \pm 10$ & & & & & \\
\hline Weight (kg) & $91 \pm 11$ & $85 \pm 10$ & $<0.001$ & $82 \pm 11$ & -9.8 & $<0.001$ \\
\hline BMI $\left(\mathrm{kg} \mathrm{m}^{-2}\right)$ & $35 \pm 4$ & $33 \pm 4$ & $<0.001$ & $31 \pm 3$ & -11 & $<0.001$ \\
\hline Waist circumference & $101 \pm 11$ & $97 \pm 11$ & $<0.001$ & $91 \pm 12$ & -9.9 & $<0.001$ \\
\hline Systolic blood pressure (mmHg) & $126 \pm 11$ & $120 \pm 11$ & 0.014 & $119 \pm 17$ & -5 & 0.008 \\
\hline Diastolic blood pressure $(\mathrm{mmHg})$ & $78 \pm 10$ & $71 \pm 8$ & $<0.001$ & $73 \pm 10$ & -6 & 0.007 \\
\hline Heart rate (bpm) & $72 \pm 9$ & $66 \pm 10$ & 0.001 & $69 \pm 10$ & -4 & 0.106 \\
\hline Fat mass & $45 \pm 3$ & $42 \pm 3$ & $<0.001$ & $41 \pm 3$ & -8 & $<0.001$ \\
\hline Energetic expenditure (kcal per day) & $1603 \pm 189$ & $1473 \pm 185$ & $<0.001$ & $1505 \pm 195$ & -6 & $<0.001$ \\
\hline Fasting plasma glucose $\left(\mathrm{mmoll}^{-1}\right)$ & $5.7 \pm 0.7$ & $5.1 \pm 0.5$ & $<0.001$ & $5.4 \pm 0.7$ & -5 & 0.003 \\
\hline Plasma glucose $\mathrm{T} 10\left(\mathrm{mmoll}^{-1}\right)$ & $5.8 \pm 0.6$ & $5.3 \pm 0.4$ & $<0.001$ & $5.5 \pm 0.70$ & -5 & 0.008 \\
\hline Fasting plasma insulin $\left(\mu \cup \mathrm{ml}^{-1}\right)$ & $8.0 \pm 3.2$ & $5.0 \pm 2.7$ & $<0.001$ & $6.8 \pm 3.3$ & -15 & 0.021 \\
\hline Fasting plasma insulin $\mathrm{T} 10\left(\mu \mathrm{U} \mathrm{ml}^{-1}\right)$ & $9.2 \pm 4.4$ & $4.8 \pm 2.4$ & $<0.001$ & $6.4 \pm 3.1$ & -30 & 0.001 \\
\hline HOMA index & $1.9 \pm 0.9$ & $1.0 \pm 0.7$ & $<0.001$ & $1.5 \pm 0.9$ & -21 & 0.071 \\
\hline HbAlc (\%) & $5.5 \pm 0.5$ & $5.2 \pm 0.4$ & 0.001 & $5.4 \pm 0.3$ & -1 & 0.081 \\
\hline Total cholesterol $\left(\mathrm{mmoll}^{-1}\right)$ & $5.4 \pm 0.7$ & $4.0 \pm 0.6$ & $<0.001$ & $4.9 \pm 0.8$ & -9 & 0.002 \\
\hline $\mathrm{HDL}$ cholesterol $\left(\mathrm{mmoll}^{-1}\right)$ & $1.3 \pm 0.2$ & $1.0 \pm 0.1$ & $<0.001$ & $1.3 \pm 0.2$ & 0 & 0.039 \\
\hline LDL cholesterol $\left(\mathrm{mmol}^{-1}\right)$ & $3.3 \pm 0.7$ & $2.5 \pm 0.5$ & $<0.001$ & $3.1 \pm 0.6$ & -6 & 0.233 \\
\hline Triglycerides $\left(\mathrm{mmoll}^{-1}\right)$ & $1.3 \pm 0.75$ & $1.0 \pm 0.42$ & 0.001 & $1.1 \pm 0.5$ & -15 & 0.039 \\
\hline $\mathrm{TSH}\left(\mathrm{mUII} \mathrm{I}^{-1}\right)$ & $1.9 \pm 1.0$ & $1.9 \pm 0.9$ & 0.978 & $2.2 \pm 1.5$ & +15 & 0.363 \\
\hline
\end{tabular}

Abbreviations: BMI, body mass index; HOMA, homeostasis model assessment; HDL, high-density lipoprotein; LDL, low-density lipoprotein; TSH, thyroid stumating hormone. Bold values indicate $P<0.05$

Table 2 Impact of short-term very low-calorie diet on microparticles, cytokines levels, fibrinolytic status (PAl-1) and endothelial damage markers

\begin{tabular}{|c|c|c|c|c|c|c|}
\hline & Baseline DO & D30 & $\begin{array}{l}\mathrm{P} \\
\text { (baseline/D30) }\end{array}$ & D90 & $\begin{array}{c}\text { Variation } \\
(D 90-D 0 / D 0), \%\end{array}$ & $\begin{array}{c}\mathrm{P} \\
\text { (baseline/D90) }\end{array}$ \\
\hline PAI-I (UA ml $\left.{ }^{-1}\right)$ & $23.7 \pm 9.8$ & $13.4 \pm 8.5$ & $<0.001$ & $14.6 \pm 9.7$ & -38 & 0.001 \\
\hline $\mathrm{VWF}\left(\mathrm{U} \mathrm{ml}^{-1}\right)$ & $106 \pm 37$ & $101 \pm 32$ & 0.123 & $109 \pm 43$ & +2 & 0.365 \\
\hline Procoagulant MPs (captured onto Annexin-5) (nM PhtdSer Eq.) & $7.3 \pm 5.6$ & $8.7 \pm 6.6$ & 0.260 & $7.3 \pm 6.2$ & 0 & 0.962 \\
\hline Procoagulant-platelet derived MPs (GPIb+) (nM PhtdSer Eq.) & $5.7 \pm 6.1$ & $3.7 \pm 2.8$ & 0.063 & $3.2 \pm 3.2$ & -43 & 0.027 \\
\hline Procoagulant-leukocyte-derived MPs (CD11a+) (nM PhtdSer Eq.) & $3.6 \pm 0.9$ & $3.3 \pm 1.0$ & 0.038 & $3.4 \pm 1.1$ & -5 & 0.259 \\
\hline $\begin{array}{l}\text { Procoagulant platelet and endothelial-derived Mps (CD31+) } \\
\text { (nM PhtdSer Eq.) }\end{array}$ & $0.16 \pm 0.18$ & $0.17 \pm 0.16$ & 0.630 & $0.10 \pm 0.17$ & -37 & 0.938 \\
\hline $\begin{array}{l}\text { Procoagulant endothelial-derived MPs) }(\mathrm{CD} 62 \mathrm{E}+)+\text { ) } \\
\text { (nM PhtdSer Eq.) }\end{array}$ & $0.12 \pm 0.16$ & $0.10 \pm 0.16$ & 0.617 & $0.12 \pm 0.26$ & 0 & 0.883 \\
\hline Microparticles-PhtSer+ (CF) (number of MP $\mu \mathrm{I}^{-1}$ ) & $2524 \pm 2571$ & $5243 \pm 7747$ & 0.057 & $2851 \pm 3257$ & +12 & 0.547 \\
\hline Platelet-derived MPs CD41+ (CF) (number of $\mathrm{MP}_{\mu} \mathrm{I}^{-1}$ ) & $1735 \pm 2524$ & $3080 \pm 6582$ & 0.189 & $1532 \pm 2540$ & -11 & 0.887 \\
\hline Eythrocytes-derived MPs (CD235+) (CF) (number of MP $\mu \mathrm{I}^{-1}$ ) & $710 \pm 845$ & $1999 \pm 456$ & 0.201 & $1102 \pm 2148$ & +55 & 0.197 \\
\hline Leukocytes-derived MPs (CD11a+, CF) (number of $M P \mu l^{-1}$ ) & $35 \pm 11$ & $33 \pm 14$ & 0.539 & $25 \pm 9$ & -28 & 0.008 \\
\hline Lymphocytic-derived MPs (CD4+) (CF) (number of $\mathrm{MP}_{\mu} \mathrm{I}^{-1}$ ) & $29 \pm 9$ & $29 \pm 9$ & 0.913 & $23 \pm 8$ & -20 & 0.022 \\
\hline $\begin{array}{l}\text { Endothelial-derived MPs (CD31+, CD41-) (CF) } \\
\text { (number of } \mathrm{MP}^{-1} \mathrm{I}^{-1} \text { ) }\end{array}$ & $9 \pm 12$ & $8 \pm 7$ & 0.939 & $6 \pm 9$ & -33 & 0.412 \\
\hline TNF $\alpha\left(\mathrm{ngl}^{-1}\right)$ & $11.3 \pm 8.9$ & $12.0 \pm 10.2$ & 0.149 & $11.1 \pm 11.2$ & -1 & 0.264 \\
\hline $\mathrm{IL}-6\left(\mathrm{ngl}^{-1}\right)$ & $14.4 \pm 10.6$ & $14.4 \pm 10.6$ & 0.667 & $23.1 \pm 31.3$ & +60 & 0.170 \\
\hline Leptin $\left(\mu \mathrm{gl}^{-1}\right)$ & $45.2 \pm 13.0$ & $20.0 \pm 9.2$ & $<0.001$ & $30.4 \pm 13.5$ & -32 & $<0.001$ \\
\hline
\end{tabular}

Abbreviations: IL-6, interleukin-6; MPs, microparticles; PAI-I, plasminogen activator inhibitor-1; TNF, tumour necrosis factor. Bold values indicate $P<0.05$.

leukocyte/lymphocyte activation, lower levels of leukocytederived MPs and lymphocyte-derived MPs were evidenced at D30 or D90 (Table 2). Variations of leptin levels between D0 and D90 were significantly correlated with weight loss $(r=0.648 ; P=0.001$ ) (Figure 2). Variations of PAI-1 levels between D0 and D90 were significantly correlated with homeostasis model assessment variations $(r=0.590$; $P=0.003)$.

Conversely, variations in erythrocyte and endothelialderived MP, endothelium damage marker $\left(\mathrm{CD} 235^{+}\right.$-MPs, $\mathrm{CD}^{+} 2^{+}$-MPs, vWF), pro-inflammatory cytokines (tumour necrosis factor- $\alpha$, interleukin-6) levels did not reach statistical significance.

\section{Discussion}

In the present study, we have shown that a short-term VLCD in obese females induces a significant reduction in PAI-1, in procoagulant platelet and leukocyte-derived MPs and in leptin levels. Our data suggest that weight reduction may 


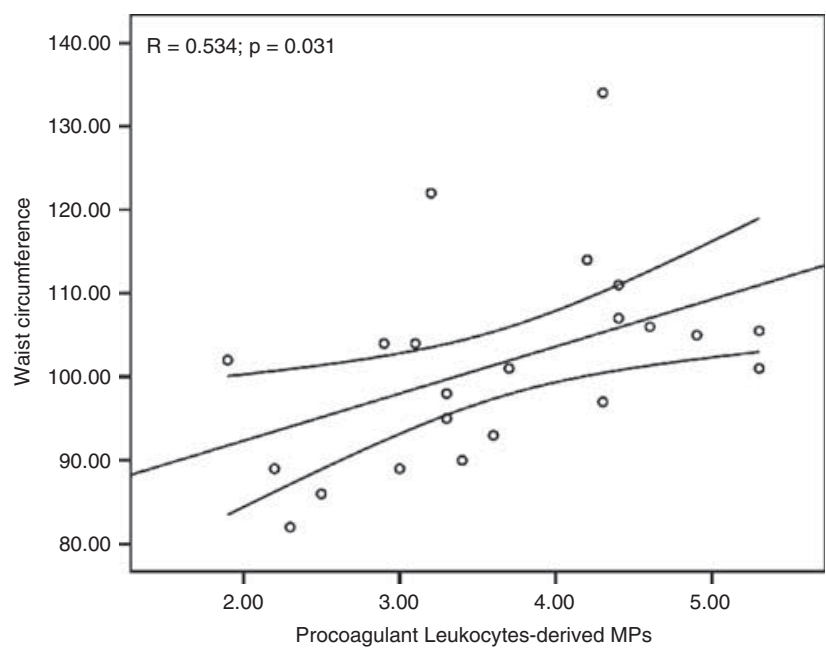

Figure 1 Correlation between waist circumference and procoagulant leukocyte-derived MPs at baseline. Procoagulant MPs were captured onto insolubilised CD11a antibody and their procoagulant potential was assessed by functional prothrombinase assay as nanomolar phosphatidylserine equivalents (nM PhtSer Eq). Correlation was computed using a non-parametric Spearman's correlation coefficient.

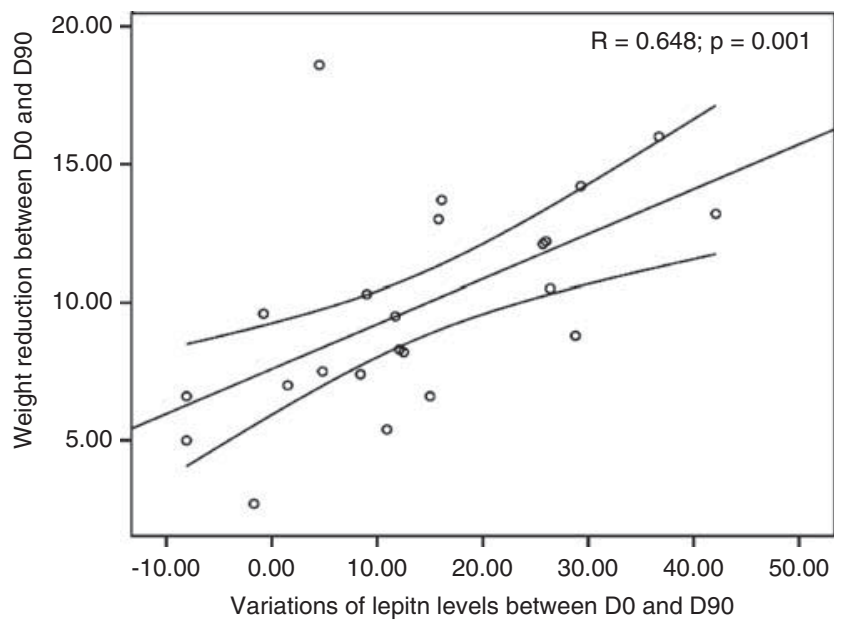

Figure 2 Correlation between variations in leptin level (D0 to D90) and weight reduction Correlation was computed using a non-parametric Spearman's correlation coefficient.

contribute to the restoration of the haemostatic balance through fibrinolysis improvement and the reduction of: (i) adipocyte-mediated inflammation (ii) platelet and leukocyte activation. Given the prime importance of leukocytederived MPs in the formation of arterial or venous thrombus, it is likely that the lowering of leukocyte activation favourably affects the thrombotic propensity described in obesity.

Obesity associated inflammation and vascular damage At baseline, the correlation between leptin levels, anthropometric parameters (weight, BMI and fat mass) or vWF, a marker of endothelium damage, is consistent with an inflammatory pathogenic pathway mediated by adipocytes. Leptin, a glycoprotein produced by mature adipocytes, resembles, both structurally and functionally, the proinflammatory cytokines such as interleukin-6 and may modulate C-reactive protein. Increased circulating leptin levels, a marker of leptin resistance, is common in obesity and independently associated with atherosclerotic burden in humans. ${ }^{11}$ In a large cohort of healthy individuals, independently of established cardiovascular risk factors, a positive relationship between coronary calcification and leptin levels has recently been reported. ${ }^{12}$ Indeed, besides its key role in the regulation of body fat stores, several reports have indicated that leptin may directly promote atherothrombosis through the enhancement of inflammatory pathways or induced platelet aggregation. Recent evidence suggests that leptin induces C-reactive protein expression in human coronary artery endothelial cells, ${ }^{13}$ promotes intimal monocyte recruitment ${ }^{14}$ and elicits macrophage foam cell formation. ${ }^{15}$

During weight loss, as observed in the present study, leptin plasma levels decrease (Figure 2). Our report of a relationship between leptin and vWF levels could reinforce the view that leptin-mediated inflammation is associated with endothelial dysfunction and subsequent atherosclerosis. Consistent with a direct role of leptin in thrombosis, experimental studies have shown that $o b / o b$ mice that are defective in leptin secretion, show impaired thrombus formation in response to vascular injury that is subsequently restored by leptin administration. ${ }^{16-18}$ However, in the present study, the lack of robust correlation between leptin and platelet-MPs, a reliable marker of platelet activation, did not substantiate the view that leptin directly modulates platelet activation, even though leptin binding to its platelet receptor promotes aggregation. ${ }^{16-18}$

Leukocyte-derived MPs could be key factors in pathways activated by obesity-mediated inflammation. In the present study, leukocyte-derived MPs were the sole parameter associated with waist circumference at baseline and at follow-up (Figure 1). Interestingly, a significant reduction in leukocyte and lymphocyte-derived MPs could be observed after weight loss (Table 2). Leukocyte-derived MPs were demonstrated to induce endothelial dysfunction, to favour the secretion of pro-inflammatory cytokines by activated endothelial cells and to promote the expression of tissue factor, the main initiator of blood coagulation. ${ }^{5}$ Notably, in healthy individuals, leukocyte-derived MPs were found to be associated with the component of metabolic syndrome or the Framingham risk score and were predictive of the extent of infra-clinical atheroma independently of traditional risk factors. ${ }^{19}$ With respect to the current knowledge, we believed that the demonstration of the reduction of leukocytesderived MPs is potentially meaningful on a pathophysiological point of view. Indeed, when considering the intricate mechanisms of thrombosis, several lines of evidences pointed at a key role for leukocyte-derived MPs. Using 
intravital real-time microscopy to monitor the thrombus growth at sites of vessel injury, several groups have established that the swift recruitment at the edge of the thrombus of leukocytes and leukocytes-derived MPs through P-selection/P-selectin glycoprotein ligand-1 interactions are mandatory for the development of the thrombus. ${ }^{20}$ In another experimental mouse model of venous thrombosis, leukocyte-derived MPs levels were negatively correlated with the thrombus weight suggesting their early incorporation within the growing thrombus. In addition, MPs reinjection led to greater thrombus weight. ${ }^{21}$ Conversely, plateletsderived MPs were positively correlated with the thrombus growth. ${ }^{21}$ It is thus likely that the accumulation of leukocyte-derived MPs harbouring TF activities is mandatory for the onset of thrombosis, whereas the levels of plateletsderived MPs mostly testify the extent of platelet stimulation. Likewise, in the setting of acute myocardial infarction, we have previously demonstrated the importance of inflammatory cells trapping together with the shedding of leukocytesderived MPs harbouring TF activities in thrombus formation. In this work, in accordance with the latter paradigm, with respect to the eventual role played by platelet-derived MPs, leukocyte-derived MPs appear to be the main contributor of TF activities at the vicinity of the arterial thrombus. ${ }^{22}$ Altogether, these data underline the prime importance of the recruitment leukocyte-derived MPs in the concentration of TF activity at site of endothelium injury.

\section{Consequences of weight reduction on platelet activation}

In our study, at baseline, higher levels of procoagulant platelet-derived MPs were observed in insulin resistant obese females (data not shown). Previous studies have suggested that insulin resistance, a common feature in obesity or metabolic syndrome, could be directly implicated in platelet stimulation. ${ }^{23}$ The possible mechanisms involved in platelet stimulation in obesity are related to: (i) the reduced sensitivity to insulin and other substances acting through intracellular cyclic nucleotides, such as nitrates and prostacyclin; (ii) the rise of cytosolic $\left(\mathrm{Ca}^{2+}\right)$; and (iii) the increased oxidative stress, which elicits isoprostane production from arachidonic acid. ${ }^{24}$ The administration of insulin inhibits platelet interaction with collagen under conditions mimicking thrombus formation and reduces healthy platelet aggregation in response to several platelets agonists whereas insulin was found to be inefficient in obese, insulin resistant patients. ${ }^{25}$ Very recently, Russo et al. ${ }^{26}$ have demonstrated that diet-induced weight loss reduces platelet activation and restores the sensitivity to the physiological anti-aggregating agents. In the present study, the drastic $43 \%$ reduction in platelet-derived procoagulant MP levels, a reliable marker of platelet stimulation, obtained after VLCD confirms the hypothesis that weight loss had a direct protective effect on platelet stimulation. Platelets are believed to constitute the main source of circulating procoagulant MPs and behave as true sensors for the haemostatic response. Several reports have shown that the interaction between platelet-derived MPs and vascular cells constitutes a checkpoint between the haemostatic and the thrombotic response. For instance, during thrombus formation, GPIb-vWF interactions not only initiate platelet arrest onto reactive vascular surfaces, but promote a drastic shedding of procoagulant MPs expressing PhtdSer and adhesion receptors (GPIb, $\alpha \mathrm{IIb} \beta 3$ ) as demonstrated in flow chambers and cone-and-plate viscosimeter studies. Platelet-derived MPs released from the surface of activated platelets are, in turn, able to stimulate leukocytes and endothelial cells, and promote monocyte diapedesis within the plaque. ${ }^{27}$

\section{Consequences of weight reduction on fibrinolysis balance}

In our study, baseline PAI-1 levels were higher in obese females with metabolic syndrome (data not shown). In adipose tissue from obese mice and humans, PAI-1 expression has been reported to be upregulated, thereby increasing plasma PAI-1 levels. In humans, increased PAI-1 expression is associated with insulin resistance identified by visceral fat accumulation. ${ }^{6}$ PAI-1, by neutralising tissue-type plasminogen activator, inhibits fibrinolysis and protects clots from early lysis. Accordingly, during myocardial infarction, the acute release of PAI-1 was found to be an independent predictor of 30 days mortality. ${ }^{28}$ In the past, prospective cohort studies conducted in atherosclerotic patients have indicated that elevated PAI-1 plasma concentrations are associated with adverse cardiovascular outcome. ${ }^{29-31}$ In dietinduced type 2 diabetic mice, both the intensity of macrophage infiltration and impaired fibrinolysis, as reflected by the measurement of the uPA/PAI-1 ratio, were found to be involved in impaired resolution of deep vein thrombosis. ${ }^{32}$ In the present study, VLCD induces a 38\% reduction in PAI-levels, a result in line with previously published data. ${ }^{33}$ As adipocytes represent an important source of PAI-1 synthesis, changes in PAI-1 levels are commonly purported to mainly reflect weight loss rather than a diminished insulin resistance. However, in the present work, PAI-1 decrease was only related to homeostasis model assessment variation, suggesting a direct impact of insulinemia on PAI-1 synthesis. Using cell culture models, previous reports have suggested that various inducers like triglycerides, free fatty acids, angiotensin II, or high doses of insulin could target the upregulation of PAI-1 synthesis in insulin resistant patients. ${ }^{34}$ Although the plasminogen counterpart was not assessed in the present study, our data suggest that weight reduction results in an overall improvement of the fibrinolytic balance.

\section{Other mechanisms potentially involved in the reduction} of MPs levels

In the present study, no definite conclusion concerning putative mechanisms possibly contributing to the lowering of circulating levels of MPs (reduced generation of MPs, 
accelerated clearance) could be raised. Although leukocytederived MPs were found to be correlated with waist circumference at baseline, at D30 and at D90, no correlation between leukocyte-derived MPs or platelet-derived MPs and the variation of the lipidic status or weight reduction could be evidenced. However, we could not exclude that the diet-reduction on cholesterol and triglycerides levels or the lowering of arterial hypertension may contribute to a diminished release of MPs. In the literature, several papers have emphasised that the ingestion of typical western diet could contribute to the shedding of endothelial-derived MPs, ${ }^{35-37}$ or associated tissue factor activity ${ }^{38}$ whereas the impact of fat ingestion on leukocyte-derived MPs levels is up to now not characterized. In addition, we could not exclude that the lowering of blood pressure could contribute to reduce platelet shedding through decrease shear stress. ${ }^{39,40}$ In the present study, because various agonists are likely to contribute to MPs shedding in the vasculature, we could not decipher the respective contribution of: (i) lipid lowering, (ii) weight reduction, (iii) inflammatory status reduction, (iv) lowering of blood pressure in the reduction of MPs levels.

Altogether, our data show that short-term VLCD leads to an improvement of the haemostatic balance through the modulation of adipocyte-induced inflammation, fibrinolysis, platelet and leukocyte activation. Albeit outside the scope of this study, given the prime importance of leukocytederived MPs in thrombotic process, it is tempting to speculate that the overall improvement of the haemostatic status brought about by weight reduction could have a favourable impact on cardiovascular outcome in obese patients.

\section{Conclusion}

In obese females, a VLCD results in an overall improvement of the haemostatic balance characterized by the reduction of PAI-levels, a fibrinolysis inhibitor, diminished platelet and leukocyte release of procoagulant MPs and a reduction in levels of the adipocyte-derived cytokine, leptin. Given the prime importance of leukocyte-derived MPs in the formation of arterial or venous thrombus, it is likely that the lowering of leukocyte activation favourably affects the thrombotic propensity described in obesity.

\section{Conflict of interest}

The authors declare no conflict of interest.

\section{Acknowledgements}

This work was supported by the PHRC (Programme Hospitalier de Recherche Clinique) regional. VLCD was provided by Insudiet (ZI du Taillis, BP 10006, 49270 Champtoceaux, France). The authors thank Drs Caneva, Perrin and Busch and the dieticians for the clinical supervision of the patients and Dr F McKenna for careful english editing.

\section{References}

1 Belza A, Toubro S, Stender S, Astrup A. Effect of diet-induced energy deficit and body fat reduction on high-sensitive CRP and other inflammatory markers in obese subjects. Int J Obes (Lond) 2009; 33: 456-464.

2 Reaven GM, Scott EM, Grant PJ, Lowe GD, Rumley A, Wannamethee SG et al. Hemostatic abnormalities associated with obesity and the metabolic syndrome. J Thromb Haemost 2005; 3: 1074-1085.

3 Goichot B, Grunebaum L, Desprez D, Vinzio S, Meyer L, Schlienger JL et al. Circulating procoagulant microparticles in obesity. Diabetes Metab 2006; 32: 82-85.

4 Ueba T, Haze T, Sugiyama M, Higuchi M, Asayama H, Karitani Y et al. Level, distribution and correlates of platelet-derived microparticles in healthy individuals with special reference to the metabolic syndrome. Thromb Haemost 2008; 100: 280-285.

5 Morel O, Toti F, Hugel B, Bakouboula B, Camoin-Jau L, Dignat-George $\mathrm{F}$ et al. Procoagulant microparticles: disrupting the vascular homeostasis equation? Arterioscler Thromb Vasc Biol 2006; 26: 2594-2604.

6 Alessi MC, Juhan-Vague I. PAI-1 and the metabolic syndrome: links, causes, and consequences. Arterioscler Thromb Vasc Biol 2006; 26: 2200-2207.

7 Alessi MC, Lijnen HR, Bastelica D, Juhan-Vague I. Adipose tissue and atherothrombosis. Pathophysiol Haemost Thromb 2003; 33: 290-297.

8 Murakami T, Horigome H, Tanaka K, Nakata Y, Ohkawara K, Katayama $\mathrm{Y}$ et al. Impact of weight reduction on production of platelet-derived microparticles and fibrinolytic parameters in obesity. Thromb Res 2007; 119: 45-53.

9 Freyssinet JM, Dignat-George F. More on: measuring circulating cell-derived microparticles. J Thromb Haemost 2005; 3: 613-614.

10 Hugel B, Socie G, Vu T, Toti F, Gluckman E, Freyssinet JM et al. Elevated levels of circulating procoagulant microparticles in patients with paroxysmal nocturnal hemoglobinuria and aplastic anemia. Blood 1999; 93: 3451-3456.

11 Martin SS, Qasim A, Reilly MP. Leptin resistance: a possible interface of inflammation and metabolism in obesity-related cardiovascular disease. J Am Coll Cardiol 2008; 52: 1201-1210.

12 Qasim A, Mehta NN, Tadesse MG, Wolfe ML, Rhodes T, Girman C et al. Adipokines, insulin resistance, and coronary artery calcification. J Am Coll Cardiol 2008; 52: 231-236.

13 Singh P, Hoffmann M, Wolk R, Shamsuzzaman AS, Somers VK. Leptin induces C-reactive protein expression in vascular endothelial cells. Arterioscler Thromb Vasc Biol 2007; 27: e302-e307.

14 Yamagishi SI, Edelstein D, Du XL, Kaneda Y, Guzman M, Brownlee M. Leptin induces mitochondrial superoxide production and monocyte chemoattractant protein-1 expression in aortic endothelial cells by increasing fatty acid oxidation via protein kinase A. J Biol Chem 2001; 276: 25096-25100.

15 O'Rourke L, Gronning LM, Yeaman SJ, Shepherd PR. Glucose-dependent regulation of cholesterol ester metabolism in macrophages by insulin and leptin. J Biol Chem 2002; 277: 42557-42562.

16 Bodary PF, Westrick RJ, Wickenheiser KJ, Shen Y, Eitzman DT. Effect of leptin on arterial thrombosis following vascular injury in mice. JAMA 2002; 287: 1706-1709. 
17 Konstantinides S, Schafer K, Koschnick S, Loskutoff DJ. Leptin-dependent platelet aggregation and arterial thrombosis suggests a mechanism for atherothrombotic disease in obesity. J Clin Invest 2001; 108: 1533-1540.

18 Konstantinides S, Schafer K, Loskutoff DJ. The prothrombotic effects of leptin possible implications for the risk of cardiovascular disease in obesity. Ann N Y Acad Sci 2001; 947: 134-141; discussion 141-142.

19 Chironi G, Simon A, Hugel B, Del Pino M, Gariepy J, Freyssinet JM et al. Circulating leukocyte-derived microparticles predict subclinical atherosclerosis burden in asymptomatic subjects. Arterioscler Thromb Vasc Biol 2006; 26: 2775-2780.

20 Falati S, Liu Q, Gross P, Merrill-Skoloff G, Chou J, Vandendries E et al. Accumulation of tissue factor into developing thrombi in vivo is dependent upon microparticle P-selectin glycoprotein ligand 1 and platelet P-selectin. J Exp Med 2003; 197: $1585-1598$

21 Ramacciotti E, Hawley AE, Farris DM, Ballard NE, Wrobleski SK, Myers Jr DD et al. Leukocyte- and platelet-derived microparticles correlate with thrombus weight and tissue factor activity in an experimental mouse model of venous thrombosis. Thromb Haemost 2009; 101: 748-754.

22 Morel O, Pereira B, Averous G, Faure A, Jesel L, Germain P et al. Increased levels of procoagulant tissue factor-bearing microparticles within the occluded coronary artery of patients with ST-segment elevation myocardial infarction: role of endothelial damage and leukocyte activation. Atherosclerosis 2009; 204: 636-641.

23 Helal O, Defoort C, Robert S, Marin C, Lesavre N, Lopez-Miranda J et al. Increased levels of microparticles originating from endothelial cells, platelets and erythrocytes in subjects with metabolic syndrome: relationship with oxidative stress. Nutr Metab Cardiovasc Dis 2010 [E-pub ahead of print 14 April 2010].

24 Anfossi G, Russo I, Trovati M. Platelet dysfunction in central obesity. Nutr Metab Cardiovasc Dis 2009; 19: 440-449.

25 Westerbacka J, Yki-Jarvinen H, Turpeinen A, Rissanen A, Vehkavaara S, Syrjälä $\mathrm{M}$ et al. Inhibition of platelet-collagen interaction: an in vivo action of insulin abolished by insulin resistance in obesity. Arterioscler Thromb Vasc Biol 2002; 22: 167-172.

26 Russo I, Traversa M, Bonomo K, De Salve A, Mattiello L, Del Mese $\mathrm{P}$ et al. In central obesity, weight loss restores platelet sensitivity to nitric oxide and prostacyclin. Obesity (Silver Spring) 2010; 18: 788-797.

27 Mause SF, von Hundelshausen P, Zernecke A, Koenen RR, Weber C. Platelet microparticles: a transcellular delivery system for RANTES promoting monocyte recruitment on endothelium. Arterioscler Thromb Vasc Biol 2005; 25: 1512-1518.
28 Collet JP, Montalescot G, Vicaut E, Ankri A, Walylo F, Lesty C et al. Acute release of plasminogen activator inhibitor-1 in ST-segment elevation myocardial infarction predicts mortality. Circulation 2003; 108: 391-394.

29 Hamsten A, de Faire U, Walldius G, Dahlén G, Szamosi A, Landou $\mathrm{C}$ et al. Plasminogen activator inhibitor in plasma: risk factor for recurrent myocardial infarction. Lancet 1987; 2: 3-9.

30 Cortellaro M, Cofrancesco E, Boschetti C, Mussoni L, Donati MB, Cardillo $\mathrm{M}$ et al. Increased fibrin turnover and high PAI-1 activity as predictors of ischemic events in atherosclerotic patients. A case-control study. The PLAT Group. Arterioscler Thromb 1993; 13: $1412-1417$

31 Arikan H, Koc M, Tuglular S, Ozener C, Akoglu E. Elevated plasma levels of PAI-1 predict cardiovascular events and cardiovascular mortality in prevalent peritoneal dialysis patients. Ren Fail 2009; 31: 438-445.

32 Bouzeghrane F, Zhang X, Gevry G, Raymond J. Deep vein thrombosis resolution is impaired in diet-induced type 2 diabetic mice. J Vasc Surg 2008; 48: 1575-1584.

33 Folsom AR, Qamhieh HT, Wing RR, Jeffery RW, Stinson VL, Kuller LH et al. Impact of weight loss on plasminogen activator inhibitor (PAI-1), factor VII, and other hemostatic factors in moderately overweight adults. Arterioscler Thromb 1993; 13: 162-169.

34 Juhan-Vague I, Morange PE, Alessi MC. The insulin resistance syndrome: implications for thrombosis and cardiovascular disease. Pathophysiol Haemost Thromb 2002; 32: 269-273.

35 Ferreira AC, Peter AA, Mendez AJ, Mendez AJ, Jimenez JJ, Mauro LM et al. Postprandial hypertriglyceridemia increases circulating levels of endothelial cell microparticles. Circulation 2004; 110: 3599-3603.

36 Tushuizen ME, Nieuwland R, Rustemeijer C, Hensgens BE, Sturk A, Heine RJ et al. Elevated endothelial microparticles following consecutive meals are associated with vascular endothelial dysfunction in type 2 diabetes. Diabetes Care 2007; 30: 728-730.

37 Sutherland WH, de Jong SA, Hessian PA, Williams MJ. Ingestion of native and thermally oxidized polyunsaturated fats acutely increases circulating numbers of endothelial microparticles. Metabolism 2001; 59: 446-453.

38 Motton DD, Mackman N, Tilley RE, Rutledge JC. Postprandial elevation of tissue factor antigen in the blood of healthy adults. Thromb Haemost 2005; 94: 504-509.

39 Nomura S, Komiyama Y. Shear stress and platelet-derived microparticles. Rinsho Byori 1997; 45: 927-933.

40 Diehl P, Nagy F, Sossong V, Helbing T, Beyersdorf F, Olschewski M et al. Increased levels of circulating microparticles in patients with severe aortic valve stenosis. Thromb Haemost 2008; 99: 711-719. 